\title{
AVALIAÇÃO DO EFEITO DE POMADA DE PRÓPOLIS PARA TRATAMENTO DE HERPES LABIAL RECORRENTE - UM ESTUDO PILOTO
}

\author{
Giliane Cristina Cantelli Ronaldi Variani ${ }^{1}$ \\ Angelita Gabriela Palludo ${ }^{2}$ \\ Nícolas Renan Pensin ${ }^{3}$ \\ Cárin Fabíola Pensin Hahn ${ }^{4}$ \\ Daniela de Cassia Faglioni Boleta-Ceranto 5
}

\begin{abstract}
VARIANI, G. C. C. R.; PALludO, A. G.; PENSIN, N. R.; HAHN, C. F. P.; BOLETA-CERANTO, D. de C. F. Avaliação do efeito de pomada de própolis para tratamento de herpes labial recorrente - um estudo piloto. Arq. Cienc. Saúde UNIPAR, Umuarama, v. 21, n. 1, p, 13-18, jan./abr. 2017.
\end{abstract}

\begin{abstract}
RESUMO: O herpes labial recorrente é uma infecção viral cuja prevalência em adultos e adolescentes varia de 10 a $15 \%$. As lesões herpéticas aparecem em quadros recorrentes e atingem a região peribucal na forma de lesões vésico-bolhosas autolimitantes. O tratamento é realizado comumente pelos medicamentos antivirais como é o caso do Aciclovir, no entanto há apenas o controle e não a cura da doença. As terapias naturais são cada vez mais procuradas pelas pessoas, dentre as quais destaca-se a utilização da própolis. A própolis é um composto resinoso produzido pelas abelhas para proteção da colmeia. Inúmeros trabalhos demonstram propriedades farmacológicas da própolis, como por exemplo, bactericida e anti-inflamatória. Pesquisas na área odontológica demonstram a utilização da própolis para diversas enfermidades bucais, incluindo o herpes labial recorrente. O objetivo deste trabalho foi analisar o efeito da própolis na forma de pomada para o tratamento de lesões herpéticas. Os resultados obtidos demonstraram que o uso da pomada de própolis a 5\% reduziu o tempo de cicatrização, bem como aumentou o intervalo entre as recidivas de lesões herpéticas. Tais resultados são promissores, entretanto, considerando ser um estudo preliminar, novos trabalhos nesta área devem ser realizados para solidificar a eficácia da própolis em pomada para tratamento de herpes labial recorrente.
\end{abstract}

PALAVRAS-CHAVE: Herpes simples. Própolis. Tratamento.

\section{“USE OF PROPOLIS OINTMENT FOR RECURRENT ORAL HERPES TREATMENT - A PILOT STUDY"}

\begin{abstract}
Recurrent oral herpes is a viral infection with 10 to $15 \%$ prevalence in adults and adolescents. The herpetic lesions appear in recurring episodes and affect the perioral region in the form of vesicobullous self-limiting injuries. It is most commonly treated by using antivirals such as acyclovir, but these are only for control rather than cure. Natural therapies are increasingly sought after, among which the use of propolis. Propolis is a resinous compound produced by bees for the protection of the hive. Several studies have shown the pharmacological properties of propolis, for example, as a bactericide and anti-inflammatory use. Research in the dental field has demonstrated the use of propolis for various oral diseases, including recurrent oral herpes. The aim of this study was to analyze the effect of propolis as an ointment for the treatment of herpetic lesions. The results showed that the use of $5 \%$ propolis ointment reduced healing time and caused an extension between relapses in patients with lesions. Despite being from a preliminary study, these results are considered promising, and further studies in the area should be held in order to solidify the effectiveness of propolis ointment for treating recurrent oral herpes.

KEY WORDS: Herpes simplex. Propolis. Treatment.
\end{abstract}

\section{Introdução}

O herpes labial recorrente (HLR) ou herpes simples é uma doença infecciosa aguda e, provavelmente, a virose mais prevalente em humanos. Os tipos mais comuns de vírus causadores do HLR são o Herpes Simples Vírus (HSV) tipos 1 e 2 . O HSV é onipresente, afeta cerca de $70 \%$ da população mundial adulta (GU, 2016), sendo que a maioria das pessoas adquirem o vírus após contato direto com fluidos corporais de indivíduos infectados. Ambos os tipos virais do herpes simples, HSV-1 e HSV-2, produzem lesões nas mucosas bucal e genital, sendo que na primeira a maior parte da casuística é causada pelo HSV-1 (MARCUCCI, 2005). Desde há algum tempo, contudo, em função da mudança de hábitos sexuais e consequente contato orogenital, há uma maior predisposição para infecções pelo HSV-1 na genitália e pelo HSV-2 na boca e lábios (WALDRON, 1998).

Após infecção pelo HSV-1, o vírus entra em um longo período de latência, alojado no gânglio trigeminal. Sua reativação esporádica ocorre devido a fatores predisponentes, capazes de diminuir a atividade do sistema imunológico do paciente (GU, 2016). O vírus é considerado dermotrópico, visto que necessita colonizar o interior de células de origem ectodérmica como mucosas, olhos, sistema nervoso central e, principalmente, a derme (TOMMASI, 2014).

Nos últimos 20 anos, a prevalência do HLR tem aumentado mundialmente e sua prevenção é um desafio. É difícil erradicar a infecção e o tratamento tem pouco impacto sobre a redução e prevenção da infecção pelo vírus. Até o momento, nenhuma vacina tem apresentado sucesso em humanos para prevenir a infecção primária do HLR (ARAIN; PARAVASTU; ARAIN, 2015).

Quase que de maneira imprescindível a primeira exposição ao HSV-1 ocorre durante a infância, entre 6 meses e 5 anos de idade, ocasionando a infecção primária denominada Gengivoestomatite Herpética Aguda ou Primária

DOI: https://doi.org/10.25110/arqsaude.v21i1.2017.6071

${ }^{1}$ Cirurgiã-dentista graduada pela Universidade Paranaense - UNIPAR.

${ }^{2}$ Cirurgiã-dentista graduada pela Universidade Paranaense - UNIPAR.

${ }^{3}$ Cirurgião-dentista graduado pela Universidade Paranaense - UNIPAR.

${ }^{4}$ Farmaucêutica graduada pela Universidade Paranaense - UNIPAR.

${ }^{5}$ Cirurgiã-dentista graduada pela Universidade Paranaense - UNIPAR, Mestre e Doutora em Fisiologia Oral - UNICAMP, professora do Curso de Odontologia da Unipar campus Cascavel. e-mail: dcboleta@unipar.br 
(GEHA). Essa exposição é geralmente subclínica, e portanto, assintomática, podendo não ser diagnosticada, ou manifestar-se clinicamente como pequenas vesículas na gengiva, que se rompem formando ulcerações características da GEHA (MARCUCCI, 2005). O período de incubação do vírus é, em média de 7 dias, após há o aparecimento dos sinais e sintomas, que incluem vesículas e gengivite difusas, evoluindo para ulcerações superficiais por toda a mucosa bucal, febre, mal-estar, dor de cabeça, linfadenopatia cervical e dor intensa, dificultando a alimentação (AMIR et al., 1999; GEORGE; ANIL, 2014).

A patologia é autolimitante e a duração das manifestações da infecção primária é de 10 a 14 dias, após um período de incubação de até 26 dias, sendo que os sinais e sintomas regridem espontaneamente (GEORGE; ANIL, 2014). Após esse período, o vírus entra em latência no gânglio do nervo trigêmeo, localizado na porção petrosa do osso temporal. A reativação ocorre esporadicamente por uma série de estímulos locais e sistêmicos, tais como dano tecidual, exposição solar e ao frio, febre, estresse físico ou emocional, ciclo menstrual e imunossupressão (ANTUNES; LULA; TONANI, 2002; PRABHU, 2007; STONA et al., 2014). O vírus HSV latente, quando reativado, é transportado no sentido do nervo sensitivo, podendo infectar as células epiteliais de modo a causar uma infecção secundária ou recorrente (MARCUCCI, 2005).

O HLR é precedido por sintomatologia prodrômica, incluindo dor, ardência, prurido e eritema. Esses sintomas antecedem em 6 a 24 horas o surgimento das primeiras manifestações clínicas, que incluem vesículas que podem evoluir para pústulas, que se rompem formando ulcerações e mais tarde serão recobertas por crostas (ANTUNES, 2002; ARAIN; PARAVASTU; ARAIN, 2015). A erupção das vesículas acontece geralmente nas regiões labial e perilabial, seguida por formação de crostas que ocorrem em aproximadamente 1 a 2 dias, com reparação em 7 a 10 dias em pacientes imunocompetentes, sendo que o tempo de reparo em pacientes imunodeprimidos tende a ser maior (MARCUCCI, 2005). As vesículas são sempre múltiplas, pequenas, formam grupos e tendem a coalescer. Rapidamente rompem liberando líquido branco-amarelado e formam crosta serossanguínea que coagula, tornando-se aderente e facilitando a regeneração tecidual (TOMMASI, 2014).

A infecção recorrente, apesar de ser mais comum nas bordas do vermelhão dos lábios, também pode acometer a mucosa bucal, geralmente, nas regiões do palato e gengiva. A possibilidade de disseminação assintomática deve ser salientada, pois a forma de transmissão mais conhecida e divulgada é a que ocorre pelo contato direto com as lesões. Entretanto, a transmissão assintomática do vírus do herpes também acontece, uma vez que, em média, 75\% dos adultos jovens são soropositivos para o HSV e esse tipo de transmissão acaba ocorrendo sem que ambas as partes envolvidas saibam (GU, 2016). O que acontece nesses casos são reativações subclínicas, nas quais não há lesões características, porém, o vírus é reativado e pode disseminar-se por meio da saliva (PEREIRA, 1996; GEORGE; ANIL, 2014).

Existem também os falsos pródromos, períodos em que os sintomas prodrômicos surgem e não são seguidos pelas lesões, no entanto, mesmo assim há a disseminação do vírus; isto tanto para o herpes labial como para o genital. Es- tes achados são importantes para orientar os pacientes a reconhecer os falsos pródromos e alertá-los sobre a alta taxa de disseminação viral e o potencial de transmissão durante estes períodos. Apesar de a disseminação ser comum nos dias em que manifestam-se os sintomas prodrômicos, a maior parte da disseminação ocorre sem ser acompanhada de nenhum sintoma (WALDRON, 1998; CHANDRASEKAR, 1999).

O diagnóstico do HLR é basicamente clínico, em alguns casos, contudo, exames laboratoriais específicos podem ser indicados (ARAIN; PARAVASTU; ARAIN, 2015). Entre os exames disponíveis para o herpes, a citologia esfoliativa e a biópsia ainda constituem-se em métodos eficientes, rápidos e de menor custo, entretanto, não diferenciam o HSV-1 do HSV-2. Em alguns casos, pode ser útil o emprego de técnicas conjugadas como a imunofluorescência direta para se distinguir os dois tipos virais (WALDRON, 1998). As técnicas altamente sensíveis, como o PCR (reação em cadeia da polimerase), também podem ser utilizadas, porém o maior obstáculo é o custo elevado (CHANDRASEKAR, 1999; LIU et al., 2015).

O tratamento para o HLR usualmente é sintomático e consiste no consumo de alimentos macios, alta ingestão de líquidos, analgésicos e antitérmicos para aliviar o desconforto (STONA, et al., 2014). Um dos fatores mais importantes no tratamento das infecções pelo HSV é o "momento exato". Para que qualquer medicamento seja eficaz, ele deve ser administrado o mais cedo possível. O momento considerado ideal para iniciar o tratamento não deve passar das 48 horas do aparecimento dos sintomas (REGEZI; SCIUBBA; JORDAN, 2008; ARAIN; PARAVASTU; ARAIN, 2015).

Foram desenvolvidas várias drogas específicas para o tratamento do herpes, mas até o momento nenhum esquema terapêutico isolado mostrou-se totalmente eficaz no controle das infecções bucais e peribucais pelo HSV. O desenvolvimento de compostos específicos para o vírus é lento em virtude da grande dificuldade em encontrar um agente viricida, capaz de agir única e exclusivamente sobre o vírus, sem influenciar na homeostasia celular (REGEZI; SCIUBBA; JORDAN, 2008). Agentes antivirais (Aciclovir) são indicados para pacientes imunossuprimidos, em casos de ulcerações severas ou quando as recorrências são frequentes, o que acelera a resolução clínica das lesões. O laser de baixa potência também tem se mostrado promissor na cicatrização das lesões e na redução da dor (STONA et al., 2014). Contudo, nenhum dos métodos terapêuticos é totalmente eficaz.

$\mathrm{O}$ uso da própolis como tratamento terapêutico natural já data de mais de 5000 anos em muitas partes do mundo (MANARA et al., 1999). A própolis é constituída de várias substâncias resinosas, gomosas e balsâmicas, de consistência viscosa, recolhida pelas abelhas de brotos, cascas de árvores ou outros vegetais, misturada às enzimas salivares (FUNARI; FERRO, 2006; SILVA-CARVALHO; BALTAZAR; ALMEIDA, 2015).

Em 1999, Manara et al., realizaram uma revisão do uso da própolis na Odontologia. A análise de diversos trabalhos permitiu-os observar atividade antibacteriana, conferida pela presença de flavonoides, ácidos aromáticos e ésteres em sua composição; ação bactericida, decorrente da presença dos ácidos ferúlico e cafeico; para mais foram observadas atividade antiviral in vitro (Herpes Simples, Influenza), em função da ação de flavonoides e derivados de ácidos aromáti- 
cos, assim como ação imunoestimuladora, hipotensiva, citostática e antiulcerativa (auxílio na cicatrização).

Desde então, muitos trabalhos avaliaram a utilização da própolis nas mais diversas especialidades da área odontológica. Pensin et al., (2009), estudaram o efeito de uma pomada de própolis a $5 \%$ em orabase para tratamento de ulcerações aftosas recorrentes, e concluíram que a pomada acelerou o processo de cicatrização das aftas, reduziu a dor, bem como prolongou o tempo entre as recorrências das lesões. Em 2014, Bretz et al., avaliaram um enxaguatório a base de própolis a $2 \%$ no tratamento da gengivite, e os resultados demonstraram que o composto teve eficácia equivalente ao controle positivo durante um período de 21 dias em que os voluntários não realizaram a higiene bucal convencional, apenas o uso do enxaguatório. Um creme dental a base de própolis apresentou alta eficácia na redução do biofilme dental, comparado a outros cremes dentais disponíveis comercialmente (BHAT et al., 2015). Al-Ostwani; Al-Monaqel; Al-Tinawi (2016), avaliaram os resultados clínicos e radiográficos do tratamento endodôntico de dentes decíduos utilizando uma pasta a base de própolis e concluíram que seu uso é promissor, considerando os efeitos antibacterianos da própolis.

Baseado no exposto e nas possibilidades múltiplas do uso da própolis na Odontologia, o objetivo deste trabalho foi avaliar o efeito de uma pomada em orabase de própolis a 5\% no tratamento de HLR.

\section{Materiais e Métodos}

Dezessete indivíduos com quadros recorrentes de herpes labial foram selecionados para participarem da pesquisa. Os critérios para inclusão foram o diagnóstico clínico de herpes simples recorrente na região peribucal, idade entre 10 e 50 anos, motivação para participarem do estudo e a assinatura de um termo de consentimento livre esclarecido (RAMOS-E-SILVA, 2006). Indivíduos com doenças sistêmicas, endócrinas, metabólicas ou reumáticas, gestantes, aqueles com alterações hormonais, imunossupressão ou que fizeram uso de corticoides nos três meses anteriores ao tratamento e os alérgicos aos componentes da pomada foram excluídos da pesquisa. Os voluntários foram analisados por um período de 07 meses, sendo instruídos a aplicarem a pomada sobre as lesões três vezes ao dia, preferencialmente durante os primeiros sinais do aparecimento, por um período de três dias. Foi solicitado que, caso houvesse algum efeito colateral, o tratamento fosse encerrado e os pesquisadores informados. Os responsáveis pela pesquisa mantiveram contato frequente com os voluntários para coletar informações sobre os dados descritos, além do que estes últimos foram instruídos a anotar em uma tabela padronizada, informações a respeito do herpes. Ao final do período de pesquisa, os quadros de avaliação foram coletados e seus dados submetidos à análise. $\mathrm{O}$ projeto foi avaliado pelo Comitê de Ética para Pesquisa em Seres Humanos da Universidade Paranaense Unipar e aprovado sob Certificado de Apresentação para Apreciação Ética 0682.0.375.000-09.

\section{Medicamentos utilizados}

Pomada de própolis em orabase a 5\% (elaborada por bioquímica habilitada, a partir de extrato de Própolis $40 \%$ adquirido da empresa Bioessens Ltda, Cotia - SP, com validade por um período de 2 anos a partir de sua fabricação). Para controle negativo foi utilizada uma pasta em orabase que serviu como veículo da própolis na elaboração da pomada.

\section{Resultados}

A amostra consistiu de um grupo composto por 17 indivíduos (13 do gênero feminino e 4 do gênero masculino). Contudo, concluíram a pesquisa apenas 15 indivíduos, pois uma voluntária desistiu e outra engravidou durante a coleta dos dados. A idade dos participantes variou de 10 a 50 anos (média 20,88 anos). Os resultados foram avaliados de acordo com os dados preenchidos pelos pacientes nas tabelas sobre as lesões (anexo 1).

Com relação aos fatores desencadeantes das lesões herpéticas, $33 \%$ dos participantes $(n=5)$ relacionaram o desencadeamento das lesões ao estresse, $7 \%$ à ansiedade $(n=$ 1), $20 \%$ a estados gripais $(n=3)$, e em contrapartida, $27 \%$ dos participantes $(n=4)$ não associaram nenhum fator específico ao desencadeamento da lesão. A exposição ao sol e os períodos pré-menstruais não foram relatados como fatores desencadeantes (Figura 1).

Figura 1: Fatores predisponentes ao surgimento das lesões do HLR apresentados em porcentagem

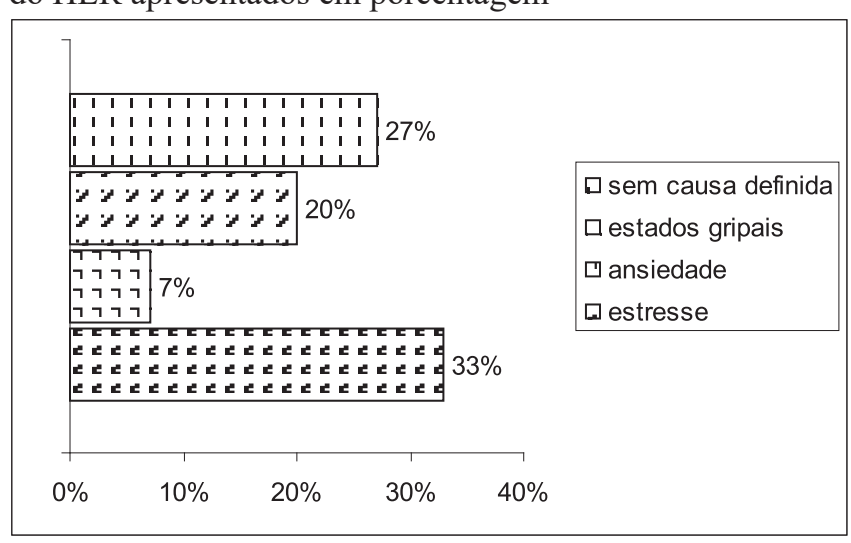

Quanto ao tipo de medicamento utilizado para o tratamento das recidivas de herpes pelos participantes da pesquisa antes do seu início, $20 \%(n=3)$ descreveram não utilizar nenhum tipo de medicamento, enquanto os outros $80 \%$ relataram usar algum dos seguintes fármacos: Aciclovir (53\%) n $=8$, Herpesine ${ }^{\circledR}(7 \%) n=1$ e protetor labial $(7 \%) n=1$.

Com relação à frequência de recidivas das lesões, $7 \%$ dos participantes $(\mathrm{n}=1)$ relataram 1 recidiva por ano, $20 \%(n=3)$ relataram 2 recidivas por ano, 33\% $(n=5)$ uma recidiva ao mês e $40 \%(n=6)$ relataram apresentarem lesões com 3 recidivas por ano (Figura 2). 
Figura 2: Frequência de recidivas das lesões herpéticas por ano, apresentadas em porcentagem

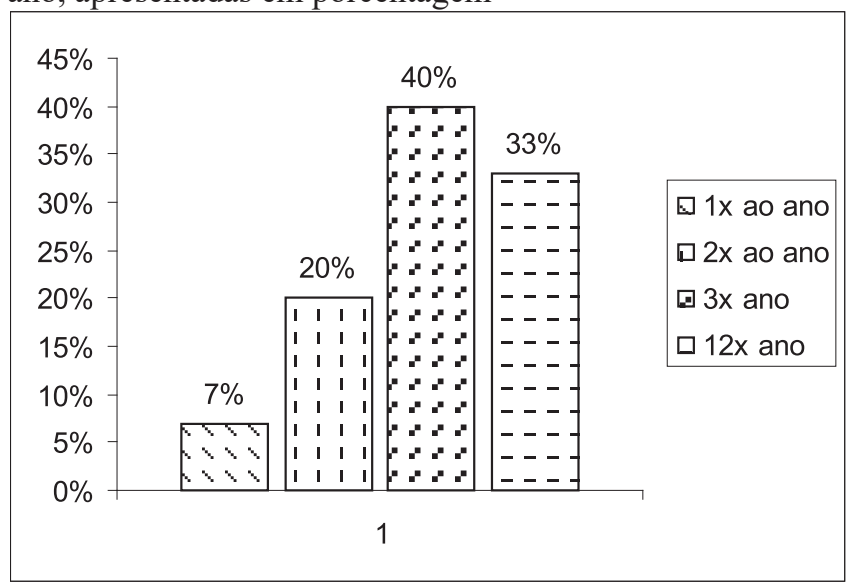

Com relação ao tratamento das lesões após o início da pesquisa, $80 \%$ dos participantes $(n=12)$ relataram que utilizaram somente a pomada de própolis e $20 \%(n=3)$ relataram que utilizaram a pomada de própolis associada ao Aciclovir.

Quanto aos resultados obtidos com a utilização da pomada de própolis para tratamento das lesões herpéticas, $73 \%(n=11)$ perceberam uma cicatrização mais rápida comparada aos medicamentos que utilizavam anteriormente, $20 \%$ $(n=3)$ relataram que não houve diferença no processo cicatricial, com a persistência das lesões, e 7\% $(n=1)$ relataram uma exacerbação da lesão após o uso da pomada (Figura 3).

Figura 3: Comportamento das lesões frente à utilização da pomada de própolis a $5 \%$

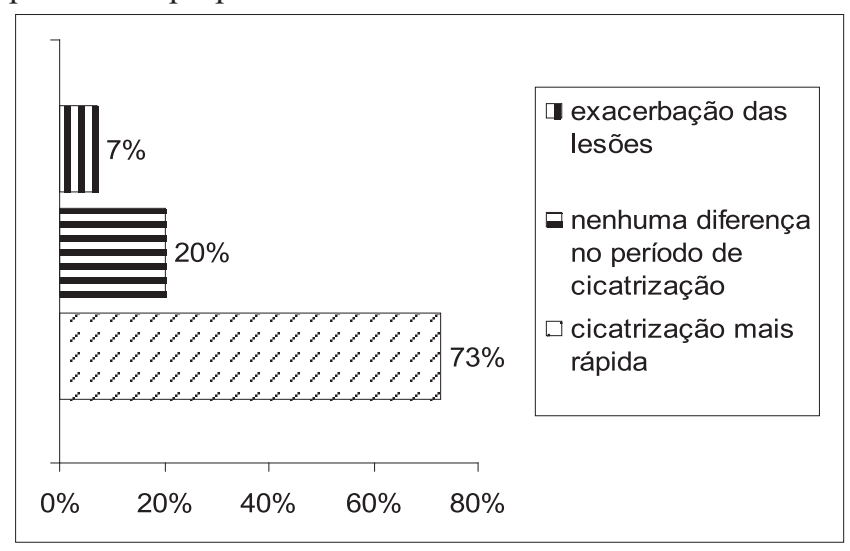

Ainda com relação à cicatrização, 73\% dos participantes $(n=11)$ relataram que as lesões cicatrizaram em um período de 3 a 6 dias, $7 \%(n=1)$ entre 6 a 9 dias, $13 \%(n=2)$ disseram que as lesões cicatrizaram entre 9 a 12 dias e $7 \%$ $(n=1)$ relataram que a cicatrização ocorreu em cerca de 15 dias (Figura 4).
Figura 4: Tempo de cicatrização das lesões com a utilização da pomada de própolis a $5 \%$

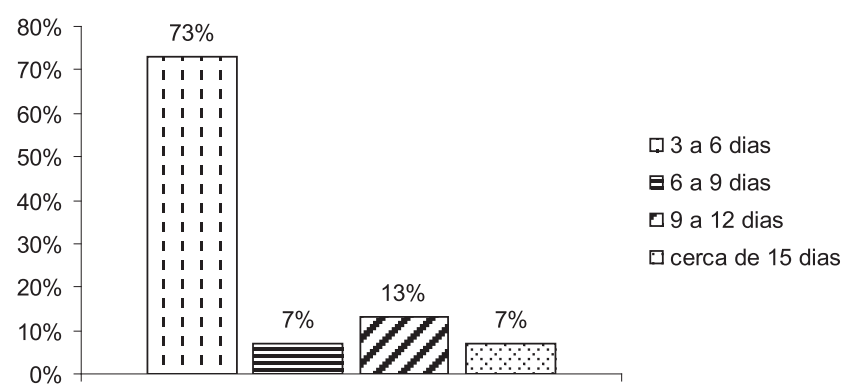

No que se refere à utilização da pomada, $60 \%(n=9)$ dos voluntários relataram que utilizaram a pomada quando houve o surgimento das lesões e continuaram utilizando até sua cicatrização, ao passo que $40 \%(n=6)$ relataram o uso já no início do prurido.

Quanto ao número de aplicações da pomada, o uso uma vez ao dia foi relatado por 7\% $(n=1)$ dos voluntários, outros $7 \%(n=1)$ relataram o uso duas vezes ao dia, enquanto $73 \%(n=11)$ informaram ter passado a pomada três vezes ao dia e os $13 \%$ restantes $(n=2)$ referiram o uso até seis vezes ao dia.

Também foi solicitado a cada voluntário que descrevesse sua impressão com relação à pomada. Dos participantes, $13 \%(n=2)$ comentaram seu contentamento por ser um medicamento natural e eficaz ao ponto de não apresentarem mais recidivas após o início do tratamento. $60 \%(\mathrm{n}=9)$ relataram que após o uso da pomada houve um aumento no tempo entre as recidivas e uma redução no tempo de cicatrização comparado ao uso de Aciclovir. 20\% $(n=4)$ dos participantes não opinaram a respeito do tratamento.

\section{Discussão}

Infecções pelos vírus herpes simples foram documentadas inicialmente na Grécia Antiga. A palavra "herpes", cujo significado é rastejar ou engatinhar em grego, foi utilizada por Hipócrates para descrever lesões que surgiam próximas umas das outras. Embora a natureza vesicular das lesões associadas com infecções herpéticas tenha sido bem caracterizada previamente, só em 1893 foi reconhecida a transmissão interpessoal das infecções herpéticas (FONSECA, 1999).

Em vista da prevalência bastante representativa de casos de HLR na população geral e do desconforto que as lesões causam, tanto no que se refere à dor quanto à estética, é importante que os profissionais da Odontologia reconheçam suas características clínicas e estejam aptos ao tratamento (MARCUCCI, 2005).

Apesar da etiologia viral da infecção herpética já estar bem determinada, a literatura aponta vários fatores como predisponentes às recidivas das lesões, tais como dano tecidual, exposição solar e ao frio, estresse físico ou emocional, ciclo menstrual, e imunossupressão (ANTUNES; LULA; TONANI, 2002; PRABHU, 2007; STONA, et al., 2014). Os resultados do presente trabalho, no que diz respeito aos fatores desencadeantes, corroboram com os encontrados na literatura, apontando o estresse, a ansiedade e fatores imunológicos como os principais.

A frequência de recidivas das lesões variou bastante 
entre os voluntários, desde uma única recorrência ao ano até uma por mês. Isso pode ser justificado tendo em vista os fatores predisponentes ao desenvolvimento do herpes, com destaque para os emocionais. Considerando que não foi avaliado o nível de estresse e ansiedade dos pacientes em cada uma das recorrências, não é possível correlacionar tais fatores, podendo oportunamente ser realizado em trabalhos futuros.

A literatura demonstra que o HLR é uma doença autolimitante, cujas lesões duram de 7 a 10 dias em pacientes imunocompetentes (MARCUCCI, 2005). Os resultados do presente trabalho apontam, de forma geral, uma redução no tempo de cicatrização das lesões, o que pode estar relacionado com a ação de flavonoides e derivados de ácidos aromáticos presentes na composição da própolis. Outros trabalhos também avaliaram a função cicatricial da própolis. Em 1996, Diaz realizou um estudo sobre a aplicação de própolis em solução alcoólica a 5\% na cura de feridas sépticas faciais em humanos e relatou que $90 \%$ dos pacientes apresentaram uma melhora total aos 7 dias de tratamento e somente 1 necessitou de período de tempo mais prolongado, 13 dias no total, para cura da ferida. Este menor tempo de cicatrização, após o uso de própolis em solução, também foi observado na mucosa de ratos por Grégio et al. (2005).

Outros trabalhos avaliando o efeito da própolis em infecções herpéticas também demonstraram sua eficácia. SHIMIZU, et al. (2011), utilizando um modelo animal concluíram que a própolis não apresenta somente uma atividade direta contra o HSV-1, mas também uma atividade imunológica contra a infeção intradérmica causada por este vírus em ratos. Os resultados de Yildirim, et al. (2016) utilizando própolis demonstraram que ela apresenta importantes efeitos antivirais comparados ao Aciclovir. Também concluíram que a associação da própolis com o Aciclovir apresentou uma atividade anti-viral mais intensa contra o HSV-1 e o HSV-2 comparado somente ao Aciclovir.

A eficácia do tratamento das lesões herpéticas depende do momento em que o medicamento é aplicado, sendo que para ser mais eficaz este deve ser administrado o mais cedo possível, logo no início dos sinais prodrômicos, não devendo passar das 48 horas do aparecimento dos sintomas (REGEZI; SCIUBBA; JORDAN, 2008). Apesar de, neste estudo, os voluntários terem sido instruídos a utilizarem a pomada logo no início dos sinais, a maioria (60\%) iniciou o tratamento somente com o surgimento das lesões e apenas $40 \%$ utilizaram conforme indicado. Este fato pode ter interferido nos resultados com relação ao tempo de cicatrização e o período dentre as recidivas, pois os vírus permanecem no local das lesões somente nas primeiras $72 \mathrm{~h}$, logo em seguida migram novamente para o gânglio sensitivo (TOMMASI, 2014), o que impediria a ação antiviral da própolis. Também é importante salientar que compostos terapêuticos devem ter ação antiviral, todavia, não podem interferir na homeostasia das células (REGEZI; SCIUBBA; JORDAN, 2008; ARAIN; PARAVASTU; ARAIN, 2015).

Apesar de todos os participantes terem sido instruídos a utilizarem a pomada três vezes ao dia, não houve homogeneidade com relação ao número de aplicações, variando de uma a seis vezes ao dia. Em vista disso, os resultados de todos os voluntários não podem ser comparados da mesma forma. Trabalhos futuros devem enfatizar aos participantes a necessidade de seguir o protocolo proposto para que não haja interferência nos resultados.

Muitas afirmações feitas sobre a ação terapêutica da própolis ainda não foram confirmadas em pesquisas. Assim, estudos estão sendo realizados para esclarecer o mecanismo de ação relacionado à sua composição química, evitando desta forma, o empirismo de seu uso, conforme revisado por Araújo et al. (2012).

Os resultados obtidos demonstram uma resposta favorável da eficácia da pomada de própolis a 5\%. Contudo, considerando a dificuldade em se conseguir a total adesão dos voluntários ao protocolo do estudo, novos trabalhos devem ser realizados para ratificar os benefícios encontrados.

\section{Conclusão}

De acordo com os resultados deste estudo, a pomada de própolis a $5 \%$ possui o potencial de acelerar o processo de cicatrização das lesões herpéticas e prolongar o tempo entre as recidivas. Estes resultados permitem aventar a possibilidade do desenvolvimento de mais uma modalidade terapêutica para o tratamento do herpes. Porém, por se tratar de um estudo piloto novas pesquisas devem ser realizadas sobre o assunto, contando com um número maior de voluntários.

\section{Referências}

AL-OSTWANI, A. O.; AL-MONAQEL, B. M.; ALTINAWI, M. K. A clinical and radiographic study of four different root canal fillings in primary molars. J Indian Soc Pedod Prev Dent. v. 34, n. 1, p. 55-59, 2016. DOI: 10.4103/0970-4388.175515.

AMIR, J. et al. The natural history of primary herpes simplex type 1 gingivostomatitis in children. Pediatr Dermatol. v. 16, n. 14, p. 259-63,1999.

ANTUNES, K. B.; LULA, M. T.; TONANI, P. C. F. Lesões bucais X Estresse. 2002. Disponível em: http://www. odontologia.com.br/artigos.asp? $\mathrm{id}=188 \&$ idesp=1\&ler $=$. Acesso em: 30 Agosto 2007.

ARAIN, N.; PARAVASTU, S. C. V.; ARAIN, M. A. Effectiveness of topical corticosteroids in addition to antiviral therapy in the management of recurrent herpes labialis: a systematic review and meta-analysis. BMC Infectious Diseases. v. 15, n. 82, 2015. DOI: 10.1186/ s12879-015-0824-0.

ARAUJO, M. A. R. et al. Mechanisms of action underlying the anti-inflammatory and immunomodulatory effects of propolis: a brief review. Rev. bras. farmacogn. v. 22, n. 1, p. 208-219, 2012. DOI:org/10.1590/S0102695X2011005000167.

BHAT, N. et al. The antiplaque efficacy of propolis-based herbal toothpaste: A crossover clinical study. J Nat Sci Biol Med. v. 6, n. 2, p. 363-368, 2015. DOI: 10.4103/09769668.160007.

BRETZ, W. A. et al. The Effectiveness of Propolis on Gingivitis: A Randomized Controlled Trial. J Altern 
Complement Med. v. 20, n. 12, p. 943-948, 2014.

DOI:10.1089/acm.2013.0431.

CHANDRASEKAR, P. H. Identification and treatment of herpes lesions. Adv Wound Care. v. 12, n. 5, p. 254-62, 1999.

DIAZ, J. C. Q. Efectos del propoleos em los tratamiento quirurgicos y lâs ulceras bucales. Rev. Cuba Estomatol. v. 33, n. 1, p. 25-27, 1996.

FONSECA, B. A. L. Clínica e tratamento das infecções pelos vírus Herpes Símplex tipo 1 e 2. Medicina, Ribeirão Preto. v. 32, p. 147-153, 1999.

FUNARI, C. S.; FERRO, V. O. Análise de própolis. Ciênc. Tecnol. Aliment. v. 6, n. 1, p. 171-178, 2006.

GEORGE, A. K.; ANIL, S. Acute Herpetic

Gingivostomatitis Associated with Herpes Simplex Virus 2: Report of a Case. J Int Oral Health. v. 6, n. 3, p. 99-102, 2014.

GRÉGIO, A. M. T. et al. Efeito da propolis mellifera sobre o processo de reparo de lesões ulceradas na mucosa bucal de ratos. Estud. Biolog. v. 27, n. 58, p. 43-47. 2005.

$\mathrm{GU}, \mathrm{H}$. Infected cell protein 0 functional domains and their coordination in herpes simplex virus replication. World J Virol, v. 5, n. 1, p. 1-13, 2016. Disponível em: http://www. wjgnet. com/2220-3249/full/v5/i1/1.htm DOI: http://dx.doi. org/10.5501/wjv.v5.i1.1

LIU, J. et al. Development and evaluation of the quantitative real-time PCR assay in detection and typing of herpes simplex virus in swab specimens from patients with genital herpes. Int J Clin Exp Med. v. 8, n. 10, p. 1875818764, 2015.

MANARA, R. L. B. et al. Utilização da própolis em Odontologia. Rev. FOB. v. 7, n. 3/4, p. 15-20. 1999.

MARCUCCI, G. Fundamentos de odontologia -

Estomatologia. 1. ed. Rio de Janeiro: Guanabara Koogan, 2005. 264 p.

PENSIN, N. R. et al. Efeito de pomada de própolis em orabase para tratamento de ulcerações aftosas recorrentes um estudo piloto. Arq. Ciênc. Saúde Unipar. v. 13, n. 3, p. 199-204, set./dez. 2009.

PEREIRA, F. A. Herpes Simplex: envolving concepts. J AM Academ Dermatol. v. 35, n. 4, p. 503-20, 1996.

PRABHU, S. R. Medicina Oral. 1. ed. Rio de Janeiro: Guanabara Koogan, 2007. 239 p.

RAMOS-E-SILVA, M. et al. Clinical Evaluation of fluid extract of chamomilla recutita for oral aphtae. J Drugs

Dermatol. v. 5, n. 7, p. 612-617, 2006.
REGEZI, J. A.; SCIUBBA, J. J.; JORDAN, R. C. K. Patologia Bucal: Correlações Clinicopatológicas. 5. ed. Rio de Janeiro: Guanabara Koogan; 2008. 417p.

SHIMIZU, T. et al. Efficacy of Brazilian Propolis against Herpes Simplex Virus Type 1 Infection in Mice and Their Modes of Antiherpetic Efficacies. Evid Based Complement Alternat Med. 2011; 2011: 976196. DOI: 10.1155/2011/976196.

SILVA-CARVALHO, R.; BALTAZAR, F.; ALMEIDAAGUIAR, C. Propolis: A Complex Natural Product with a Plethora of Biological Activities That Can Be Explored for Drug Development. Evid Based Complement Alternat Med. Volume 2015 (2015), Article ID 206439, 29 pages. http://dx.doi.org/10.1155/2015/206439.

STONA, P. et al. Recurrent Labial Herpes Simplex in Pediatric Dentistry: Low-level Laser Therapy as a Treatment Option. Int J Clin Pediatr Dent. v. 7, n. 2, p. 140-143, 2014. DOI: 10.5005/jp-journals-10005-1252

TOMMASI, M. H. M. T. Diagnóstico em Patologia Bucal. 4. ed. Rio de Janeiro: Elsevier, 2014. 480 p.

WALDRON, C. A. Patologia Oral e Maxilofacial. 3 ed. Rio de Janeiro: Guanabara Koogan, 1998. 820 p.

YILDIRIM, A. et al. Antiviral Activity of Hatay Propolis Against Replication of Herpes Simplex Virus Type 1 and Type 2. Med Sci Monit. v. 9, n. 22, p. 422-430, 2016.

Recebido em: 07/04/2016 Aceito em: 10/05/2016 